\title{
Fusion of human bone hemopoietic stem cell with esophageal carcinoma cells didn't generate esophageal cancer stem cell
}

\author{
H. FAN ${ }^{1}$, S. $L U^{2, *}$ \\ ${ }^{1}$ Department of Oncology, Shanghai Renji Hospital, Shanghai Jiaotong University School of Medicine, China; ${ }^{2}$ Department of Etiology and Carcinogenesis, \\ Chinese Academy of Medical Sciences and Peking Union Medical College, Beijing, China
}

*Correspondence: hbfan2012@126.com

Received September 25, 2013 / Accepted January 31, 2014

\begin{abstract}
Prior studies showed that cell fusion between bone marrow-derived cell (BMDC) and somatic cell might be the origin of cancer stem cell. Our previous study suggested that cell fusion of human bone marrow-derived mesenchymal stem cell (MSC) with esophageal cancer cell did not generate cancer stem cells. But up to now, the origin of cancer stem cell is still ambiguous. In this study, we carried out the cell fusion experiment between hemopoietic stem cells (HSCs) and human esophageal cancer cells, and found that cell fusion slowed the growth speed of esophageal cancer cells and decreased the clone formation ability and tumorigenicity in NOD/SCID mice. In addition, cell fusion did not increase the ratio of side population (SP) cells and the resistance to chemotherapeutic drugs. Collectively, our data indicated that cell fusion between HSCs and esophageal cancer cells has a therapeutic effect rather than generate cells with characteristics of esophageal cancer stem cells.
\end{abstract}

Key words: cell fusion, hemopoietic stem cells, esophageal cancer, cancer stem cells

Current opinions in the field of cancer origin intensively focused upon that most cancers arise from a single cell, cancer stem cell (CSC) [1]. CSC is a kind of cell which has the ability to self-renew, dividing to give rise to another malignant stem cell and a cell that gives rise to the phenotypically diverse tumor cell population $[2,3]$. But up to now, the origin of cancer stem cell is still ambiguous. Cell fusion is a normal physiological process that occurs in diverse organisms and plays essential roles in fertilization and development of various organ systems. When cell fusion goes awry, however, it may lead to cancer [4]. The idea of cell fusion as a key driver of oncogenesis dates back to early twentieth century [5]. At present, there is an increasing body of evidence indicating that the cell fusion leads to cancer stem cell initiation [1,6-8]. Compared with the classic model of oncogenesis through linear accumulation of mutant alleles, cell fusion efficiently creates nonlinear assortments of genetic rearrangments and associated phenotypic alterations [1]. The observation that bone marrow-derived cells can fuse with local somatic cells in vivo in the event of tissue damage and inflammation raised the interesting possibility that cell fusion might provide a means for the generation of CSCs and neoplasm [1]. Our previous study showed that fusion between MSCs and esophageal cancer cells didn't contribute to the ori- gin of esophageal cancer stem cell [9]. So cell fusion of HSCs with cancer cells might contribute to the origin of cancer stem cell. In order to verify this hypothesis, we conducted cell fusion tests of HSCs with esophageal cancer cells.

\section{Material and methods}

Cell culture. Human esophageal cancer cell line EC9706 was established by the Cancer Institute, Chinese Academy of Medical Science. Both EC9706 and fusion cells (FCs) were maintained in DMEM (Gibco, USA) culture medium supplemented with $10 \%$ FBS, 100 units $/ \mathrm{ml}$ penicillin $\mathrm{G}$ and $100 \mu \mathrm{g} / \mathrm{ml}$ streptomycin. All these cells were maintained in a humidified $5 \% \mathrm{CO}_{2}$ incubator in $37^{\circ} \mathrm{C}$. Human bone marrow hemopoietic stem cells were taken from healthy adult and the cells were cryopreserved in liquid nitrogen for use.

Cell fusion and sorting. Heterokaryons were generated by fusing hHSCs and EC9706 cells using 50\% polyethylene glycol, pH7.4 (PEG 1500; Roche, Cat.783641) according to the method on "Current Protocols in Stem Cell Biology" [10]. The labeled cells mixed (EC cells: hHSCs $=1: 10$ ) and centrifuged at $400 \mathrm{~g}$ for $5 \mathrm{~min}$, after the supernatant was completely removed $1 \mathrm{ml}$ of PEG (prewarmed to $37^{\circ} \mathrm{C}$ ) was 
added dropwise to the pellet over $60 \mathrm{sec}$ in a $37^{\circ} \mathrm{C}$ water bath and incubated for $90 \mathrm{sec}$ with constant stirring. Then, $4 \mathrm{ml}$ of serum-free DMEM pre-warmed at $37^{\circ} \mathrm{C}$ were carefully added over a period of $2 \mathrm{~min}$, followed by $6 \mathrm{ml}$ of DMEM and incubation at $37^{\circ} \mathrm{C}$ for $3 \mathrm{~min}$. After washed twice with $50 \mathrm{ml}$ of serum-free DMEM immediately to reduce PEG toxicity, the pellet was allowed to swell in complete medium for $5 \mathrm{~min}$. Cell mixtures were gently re-suspended with PBS, and were isolated by $\mathrm{CD} 34^{+} \mathrm{CD} 38 \mathrm{Scal}^{+}$immunomagnetic beads. The column was washed with $500 \mu \mathrm{L}$ Dilution Buffer apart from magnetic field. The solution obtained included CD $34^{+} \mathrm{CD} 38^{-} \mathrm{Scal}^{+}$cells and HSCs. Then cell mixtures were gently re-suspended with DMEM with $10 \%$ FBS, and incubated in a humidified $37^{\circ} \mathrm{C}$ incubator with $5 \% \mathrm{CO}_{2}$. For HSCs cannot grow in DMEM with 10\% FBS, only FCs would survival in this circumstance.

Cell growth curve. FCs and EC9706 cells were incubated at $1 \times 10^{3}$ cells per well in 96-well plates, at a total volume of $200 \mu$. Each subpopulation had 10 replicates cultured in DMEM with $10 \%$ FBS. The culture medium was removed each day in the following seven days and MTT methods were done as routine. According to the absorbance of each well from BioRad enzyme reader at the wavelength of $570 \mathrm{~nm}$, we draw the growth curve according to the data.

Colony formation assay. Aliquots of logarithmically growing cells (500 cells) in single cell suspensions were plated on 6-well plates and cultured in complete medium for 14 days. For visualization, colonies were stained with crystal violet in $50 \%$ methanol and $10 \%$ glacial acetic acid for counting. After washing out the dye, we counted the clone number that contained $>50$ cells and compared the results. The clone formation efficiency (CFE) was the ratio of the clone number to the planted cell number.

Xenograft assays in immunodeficient mice. NOD/SCID mice (5 6 weeks old) were provided from animal institute of Chinese Academy of Medical Science \& Peking Union Medical College (CAMS\&PUMC) and maintained in micro-isolator cages there. All experiments were approved by the animal care committee of CAMS\&PUMC. $5 \times 10^{5}$ FCs and $5 \times 10^{5}$ EC9706

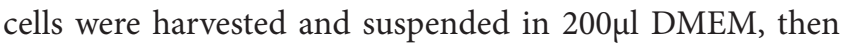
were injected into the left axillary regions of the mice. The mice were monitored twice a week for palpable tumor formation and were sacrificed at 4 weeks after transplantation for detecting the tumor formation. Tumors were measured with vernier caliper, and then weighed, pictured. Part of subcutaneous tumor tissues were collected, fixed in $10 \%$ formaldehyde and embedded in paraffin for hematoxylin-eosin staining to make sure the tumor pathology.

Drug sensitivity assays to anti-tumor drugs. We tested the sensitivity of FC and EC9706 to the representative antitumor drugs for esophageal carcinoma treatment, cisplatin and 5-FU, using MTT assay. Two kinds of tumor cells were cultured in the 96-well plates, $1 \times 10^{3}$ cells per well. The concentrations of cisplatin were $10 \mu \mathrm{mol} / \mathrm{L}$ and $20 \mu \mathrm{mol} / \mathrm{L}$, and those of $5-\mathrm{Fu}$ were $1 \mathrm{mg} / \mathrm{L}$ and $5 \mathrm{mg} / \mathrm{L}$ respectively. After 72 hours of culture, the absorbance of each well was determined with the Bio-Rad enzyme reader using MTT assay. The rate of inhibition was calculated according to the formula: (1-absorbance of experimental well / absorbance of control well) $\times 100 \%$.

Analyzing and sorting of esophageal carcinoma cell lines by FACS. FCs and EC9706 cells were analyzed by FACS when cells in a logarithmic growth phase. Cells were digested with $0.025 \%$ trypsin and $1 \mathrm{mM}$ EDTA, washed with calcium/magnesium free phosphate buffer saline (PBS), then re-suspended in DMEM culture medium without FBS, with the concentration of $1 \times 10^{6} \mathrm{cells} / \mathrm{ml}$ and incubated in $37^{\circ} \mathrm{C}, 5 \% \mathrm{CO}_{2}$ incubator for ten minutes. After that DNA binding dye Hoechst 33342 (Sigma) were added at the final concentration of $7.5 \mu \mathrm{g} / \mathrm{ml}$ either alone or in the presence of $100 \mu \mathrm{mol} / \mathrm{L}$ verapamil(Merck, Germany) and incubated for 90 minutes in incubator in dark with interval mixing. After incubation, cells were washed with cold PBS and filtered through a $40 \mu \mathrm{m}$ cell strainer to obtain single-suspension cells. Before 5 minutes of cells analyzing and sorting by FACS (FACSDiva Option, Becton Dickinson), final concentration of $1 \mu \mathrm{g} / \mathrm{ml}$ propidium iodide (Sigma, USA) was added. Hoechest 333342 was excited with UV laser at 350nm and fluorescence emission was measured with 405/BP309 (Hoechst blue) and 570/BP20 (Hoechst red) optical filters. Propidium iodide labeling was measured through the 630/BP30 filter for the discrimination of dead cells. PI negative cells were sorted into two subpopulations, Hoechst 33342 negative cells, SP cells, whose ability of fluorescent efflux could be blocked by verapamil, and Hoechst 33342 positive population (non-SP).

Statistical methods. Microsoft Office Excel 2010 and the statistical software SPSS20.0 were used in data processing and in analyzing the significance between fusion cells and EC9706 cells with the unpaired or paired $t$ test. $P$ values $<0.05$ were considered significant. Data were expressed as the mean $\pm \mathrm{SD}$ from at least three independent experiments.

\section{Results}

Cell fusion inhibited the growing ability of EC9706. MTT methods were conducted to determine the cell growth rate. After day 4, the FCs and EC9706 cells reached a logarithmic growth phase in DMEM. In contrast, FCs grew slowly in DMEM until day 7, which was much slower than EC9706. (Figure 1A)

Cell fusion inhibited the colony formation ability of EC9706. After 9 days of culture, most clones had reached $>50$ cells. We counted the clone number and found that the mean CFE was $28.8 \%$ and $46.2 \%$ in FCs and EC9706 cells, respectively. Statistical analysis showed significant differences in CFE between them $(p<0.01$; Figure $1 \mathrm{~B}$ and $\mathrm{C})$. These findings showed FC grew more slowly than EC9706, further indicating that HSCs inhibited the EC9706 after fusion.

Cell fusion inhibited the tumorigenicity. FCs grew more slowly in growing curve and plate clone forming test. We further examined the tumorigenesis in vivo with NOD/SCID mice engraftments. Mice were euthanatized 4 weeks after 

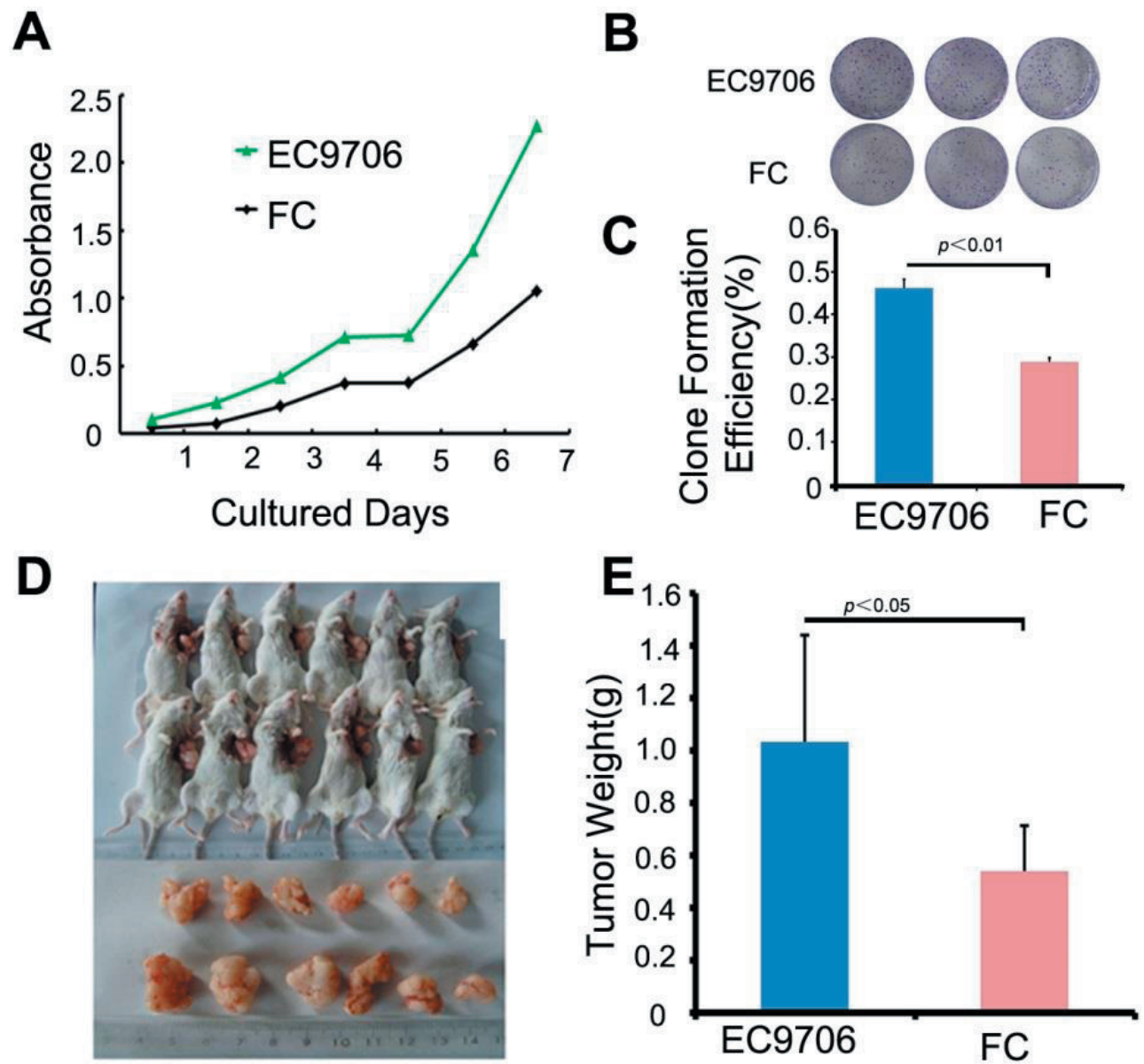

Figure 1. Proliferation of FC and EC9706. A, Cell growth curve of FC and EC9706 in DMEM, the growth curves of FC grew more slowly than EC9706 $(p<0.05)$. B and C, Clone formation of FC and EC9706 results and statistical analysis. The CFE of FCs was lower than that of EC9706 cells (p<0.05). $\mathrm{D}$ and E, Tumor formation in NOD/SCID mice and statistical analysis. Injection sites of NOD/SCID mice inoculated with $5 \times 10^{5} \mathrm{FCs}$ or EC9706 cells and euthanatized 4 wks later. All mice formed tumors, but the tumor weight of FC was lighter than that of EC9706.

inoculation, and the tumors were weighed. All mice formed tumors in EC9706 group and fusion cells group. But the weight of tumors in fusion groups were significantly lighter than those of EC9706 (Figure $1 \mathrm{D}$ and E).

Cell fusion didn't increase the ratio of SP cells. After excluding dead cells and cellular debris based on scatter signals and propidium iodide fluorescence, the FCs and EC9706 cells were sorted. The $\mathrm{P} 3$ gate showed the SP cells that were Hoechst 33342 negative/dim, and the $\mathrm{P} 4$ gate indicated the NSP cells that were Hoechst 33342 positive. SP cells occupied $0.3 \%$ in FC cells and $0.2 \%$ in EC9706. When pre-incubated with verapamil for $30 \mathrm{~min}$, the percentage of SP cells dropped to $0.1 \%$ of the total cells (Figure 2), which is consistent with reports that Hoechst 33342 exclusion is verapamil sensitive [11] (Figure 2).

Fusion cell didn't acquire increased ability of resistance to anti-tumor drugs. MTT assay was used to evaluate the sensitivity of FC and EC9706 cells to chemotherapeutic agents, such as 5-Fu and cisplatin. 5-Fu and cisplatin are commonly used for the chemotherapy of esophageal cancer. After exposure with $1 \mathrm{mg} / \mathrm{ml}$ and $5-\mathrm{mg} / \mathrm{ml} 5-\mathrm{Fu}$, the viability of the FC cells was slightly lower compared to EC9706 cells $(p>0.05)$ (Figure 3A) . The results were similar in the case of cisplatin treatment ( $p>0.05$ for both 10 and $20 \mu \mathrm{mol} / \mathrm{L}$ ) (Figure 3B). These results demonstrated FCs did not acquire increased ability of resistance to chemotherapeutic drugs.

\section{Discussion}

Recently, cell fusion has been conjectured to be involved in the generation of CSCs and bone marrow-derived stem cell fused with a local differentiated cell might play a role in these hypotheses. To investigate the role of HSCs in cell fusion hypothesis, we carried out fusion between HSCs and EC9706.

Self-renewal and differentiation are properties of CSCs that allow them to generate additional CSCs. These make CSCs to have higher tumorigenic ability than normal cancer 
EC9706
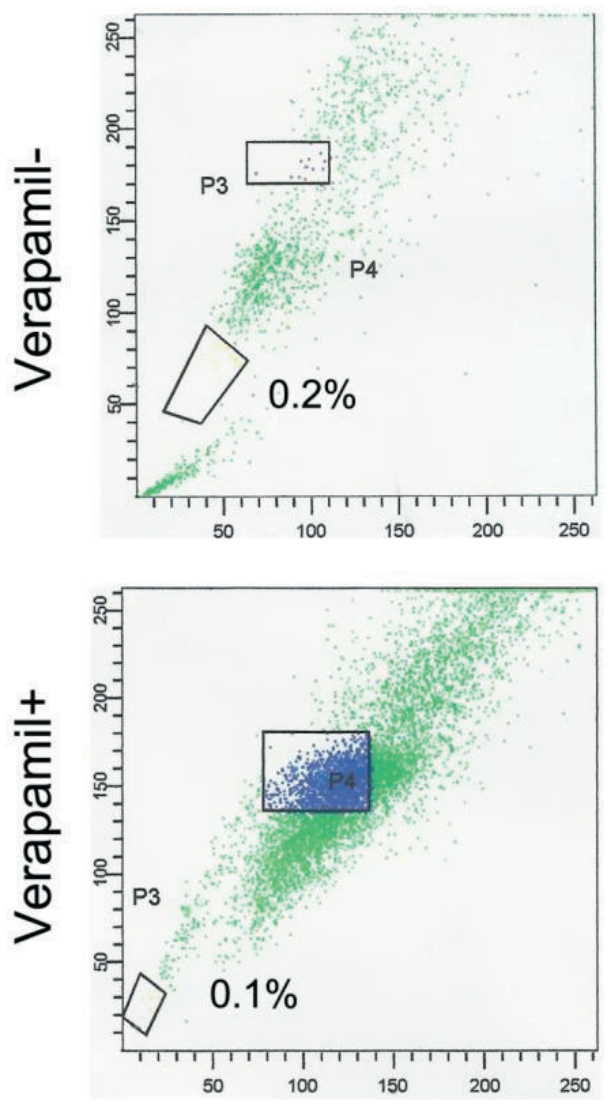

FC
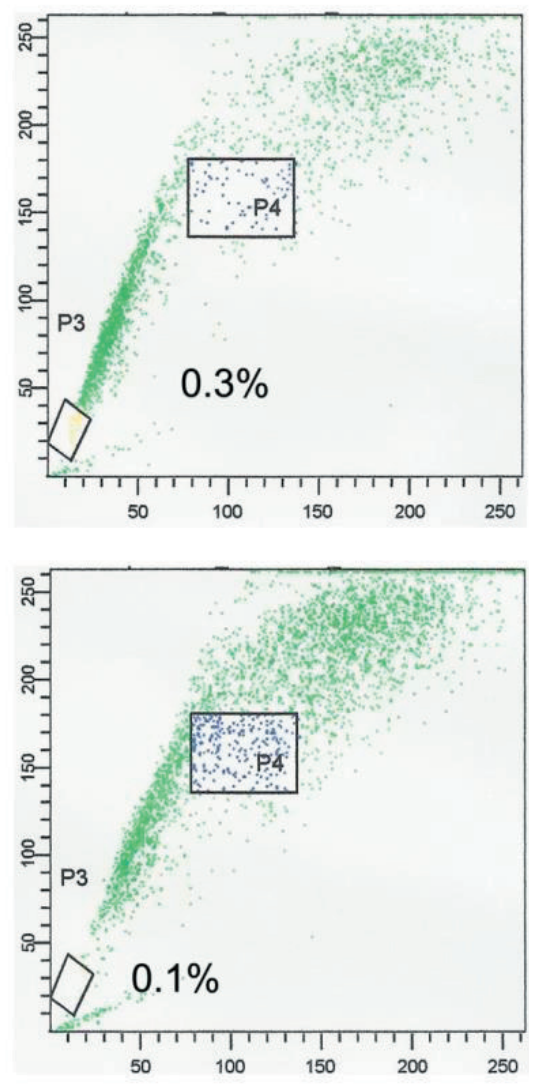

Figure 2. SP cell analysis. The FCs contained $0.3 \%$ SP cells, and the EC9706 cells contained $0.2 \%$ SP cells. The ratio of SP cells was $0.1 \%$ after verapamil treatment. The ratio of SP cells in FCs was not significantly different from that in EC9706 cells.

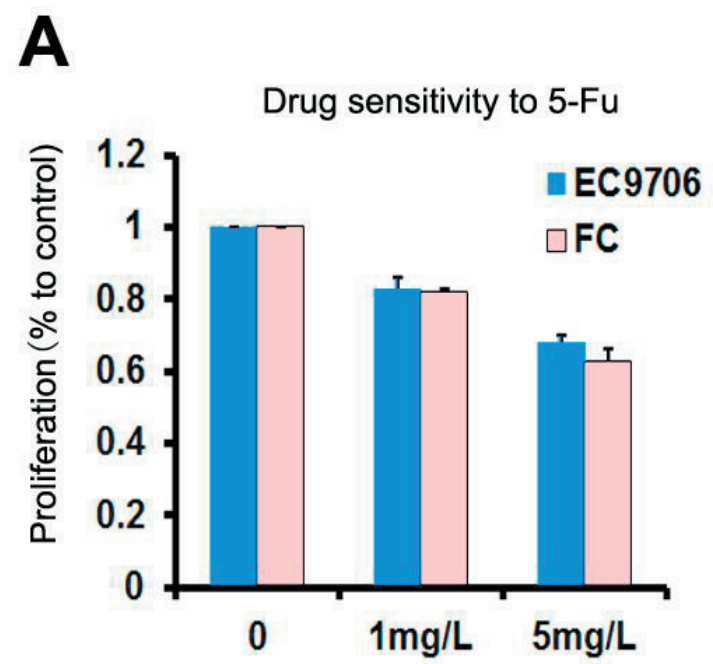

B

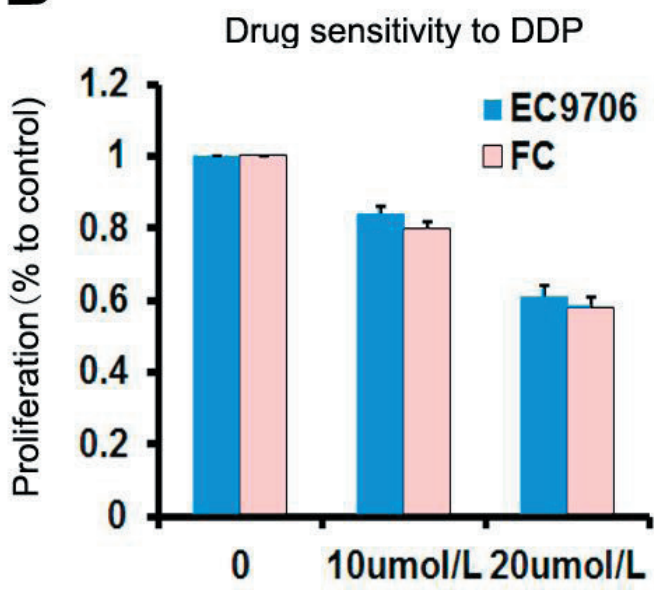

Figure 3. The sensitivity of FCs and EC9706 cells to 5-Fu and DDP. Two kinds of cells showed similar resistance to 5-Fu and DDP. 
cells. Our in vitro experiments revealed that FCs grew more slowly than EC9706 cells. In addition, in vivo treatment of NOD/SCID mice showed that the tumor formation ability of FCs was lower than EC9706 cells. Houghton et al transplanted male mice's bone marrow to lethally irradiated female C57BL/6 mice, and Y-chromosome was detected in gastric cancer tissue, implying that bone marrow-derived cells might be involved in the formation of gastric cancer by fusion with epithelia cell [12]. Contrarily, we found that the colony formation ability and tumorigenicity of esophageal cancer cell declined after fusion with HSCs, opposite to our expectation. Bone marrow-derived cells include HSCs and MSCs. Our previous study had shown that fusion between MSCs and esophageal cancer cells didn't increase the tumorigenicity of esophageal cancer cells, indicating that cell fusion with MSCs might not contribute to the origin of cancer stem cell [9]. HSC is another bone marrow-derived cell. In 1970s, Henry Harris carried out a series of cell fusion experiments. Fusion of mouse breast cancer cells with L cells, fibroblasts and L cell derivatives of low tumorigenicity, suppressed the malignancy of the tumor cell and reduced the tumorigenicity of tumor cells [13-15]. Only cell fusion between tumor cells increased tumorigenicity of tumor cell [16]. Additionally, Rizvi AZ et al also reported that transplanted BMDCs fuse with both normal and neoplastic intestinal epithelium resulted in stable hybrid cells, but the fusion cells did not initiate cancer of the small intestine [17]. These studies support our results: cell fusion inhibited the tumorigenicity of tumor cells. Previous studies also indicated fusion of BMDCs might play an important role in regeneration of damaged tissue [18-21]. Thus HSCs might still have a therapeutic effect rather than an origin of malignance.

Side population (SP) refers to cell clusters with strong ability to efflux DNA dye Hoechst 33342 via ABC transporters, whose activity can be inhibited by verapamil. SP is regarded as a universal hallmark of stem cells, which means SP cells possess stem cell potentials. Up to now, there aren't special cell surface markers to isolate esophageal cancer stem cells. Huang et al found SP cells had cancer stem like properties in esophageal cancer cell lines [22]. Wang et al used SP method to isolate nasopharyngeal cancer stem cell and found that the SP ratio declined from $99 \%$ initially to $9.6 \%$ after culturing for 20 days [23]. On the basis of these studies, if cell fusion generates cancer stem cells, the ratio of SP cells in FCs should be higher than in EC9706 initially. We investigated ratios of SP cells in FCs and EC9706 cells. The result showed that the ratios were initially both low and not significantly different in these two kinds of cells (FC: 0.3\% ; EC9706: 0.2\%), which indicated that cell fusion might not generate esophageal cancer stem cell because SP ratio would not increase but only decrease after culturing.

The CSC theory suggests that not all cancer cells are identical [24]. Tumors may have a built-in population of pluripotent cells that are resistant to chemotherapy, which may repopulate the tumor after other cells are killed [25]. The Hoechst 33342 exclusion ability conferred by $\mathrm{ABC}$ transporters forms the basis for the SP phenotype, and many chemical drugs may be pumped out of cells in the same way. Because chemotherapy is the primary method of treatment for cancer patients, we also conducted chemosensitivity assays to investigate whether FCs could resist treatment more readily than EC9706 cells. In the drug sensitivity assay, FCs were not more resistant to 5-fluorouracil and cisplatin. This suggested that FCs did not acquire the property of drug resistance of CSCs, which further indicated that cell fusion might not generate cancer stem cell. In recent years, some researches showed that distinct CSCs subpopulations exhibit different properties. Hermann et al identified two distinct populations of CSCs in pancreatic cancer: $\mathrm{CD} 133^{+}$pancreatic CSCs were exclusively tumorigenic and highly resistant to standard chemotherapy, whereas CD133+ $\mathrm{CXCR}^{+}$pancreatic CSCs, being present in the invasive front of the tumor, determined the metastatic phenotype [26]. Accordingly, in our study, the FCs might be one subgroup of CSCs which were not resistant to chemotherapy. However, Hermann's study further indicated that transplantation of both CSC populations into athymic mice showed a similar tumor development [26]. In our study, tumorigenicity of FC was lower than esophageal cancer cell, implying that FC was not one of subgroups of cancer stem cells, and it did not acquire the characteristics of cancer stem cell as well.

In conclusion, cell fusion between HSCs and EC9706 did not generate cells with increased potential of proliferation, self-renewal, differentiation, resistance to chemotherapy, and tumor formation ability. In particular, we found that cell fusion slowed the growth speed of esophageal cancer cells and decreased the clone formation ability and tumorigenicity in NOD/SCID mice. Additionally, cell fusion did not increase the ratio of SP cells and the resistance to chemotherapeutic drugs. Although our data directly demonstrated that HSCs fused with esophageal cancer cells did not lead to increased tumorigenic ability, we cannot rule out alternative mechanisms for HSCs incorporation into esophageal cancer cells. There is evidence for the involvement of BMDCs in tumorigenesis, as proved by the contribution of these cells to tumor vasculature [27] and in initiation of the angiogenic switch which is important for tumor progression [28]. In short, the origin of CSC needs further investigation.

Acknowledgments: No potential conflicts of interest were declared. We thank Dr. Quanli Gao for cell fusion and providing human bone marrow HSCs.

\section{References}

[1] BJERKVIG R, TYSNES BB, ABOODY KS, NAJBAUER J, TERZIS AJ. Opinion: the origin of the cancer stem cell: current controversies and new insights. Nat Rev Cancer 2005; 5: 899-904. http://dx.doi.org/10.1038/nrc1740

[2] HUNTLY BJ, GILLILAND DG. Leukaemia stem cells and the evolution of cancer-stem-cell research. Nat Rev Cancer 2005; 5: 311-321. http://dx.doi.org/10.1038/nrc1592 
[3] SINGH SK, HAWKINS C, CLARKE ID, SQUIRE JA, BAYANI $\mathrm{J}$ et al. Identification of human brain tumour initiating cells. Nature 2004; 432: 396-401. http://dx.doi.org/10.1038/ nature 03128

[4] DUELLI D, LAZEBNIK Y. Cell fusion: a hidden enemy? Cancer Cell 2003; 3: 445-448. http://dx.doi.org/10.1016/ $\underline{\text { S1535-6108(03)00114-4 }}$

[5] AICHEL O. Über Zellverschmelzung mit qualitativ abnormer Chromosomenverteilung als Ursache der Geschwulstbildung. Vorträge Und Aufsätze Über Entwicklungsmechanik Der Organismen 1911.

[6] SHACKLETON M, QUINTANA E, FEARON ER, MORRISON SJ. Heterogeneity in cancer: cancer stem cells versus clonal evolution. Cell 2009; 138: 822-829. http://dx.doi. org/10.1016/j.cell.2009.08.017

[7] PAWELEK JM. Tumour-cell fusion as a source of myeloid traits in cancer. Lancet Oncol 2005; 6: 988-993. http://dx.doi. org/10.1016/S1470-2045(05)70466-6

[8] KERBEL RS, LAGARDE AE, DENNIS JW, DONAGHUE TP. Spontaneous fusion in vivo between normal host and tumor cells: possible contribution to tumor progression and metastasis studied with a lectin-resistant mutant tumor. Mol Cell Biol 1983; 3: 523-538.

[9] WANG Y, FAN H, ZHOU B, JU Z, YU L et al. Fusion of human umbilical cord mesenchymal stem cells with esophageal carcinoma cells inhibits the tumorigenicity of esophageal carcinoma cells. Int J Oncol 2012; 40: 370-377.

[10] THORSTEN SCHLAEGER, EDITOR. Curr Protoc Stem Cell Biol, New York: John Wiley \& Sons, 2009.

[11] MORGAN SA, WATSON JV, TWENTYMAN PR, SMITH PJ. Flow cytometric analysis of Hoechst 33342 uptake as an indicator of multi-drug resistance in human lung cancer. Br J Cancer. 1989; 60: 282-287. http://dx.doi.org/10.1038/ bjc. 1989.271

[12] HOUGHTON J, STOICOV C, NOMURA S, ROGERS AB, CARLSON J et al. Gastric cancer originating from bone marrow-derived cells. Science 2004; 306: 1568-15671. http:// dx.doi.org/10.1126/science.1099513

[13] KLEIN G, BREGULA U, WIENER F, HARRIS H. The analysis of malignancy by cell fusion. I. Hybrids between tumour cells and L cell derivatives. J Cell Sci 1971; 8: 659-672.

[14] HARRIS H, WIENER F AND KLEIN G. The analysis of malignancy by cell fusion. 3 . Hybrids between diploid fibroblasts and other tumour cells. J Cell Sci 1971; 8: 681-692.

[15] WIENER F, KLEIN G AND HARRIS H. The analysis of malignancy by cell fusion. IV. Hybrid between tumour cells and a malignant L cell derivative. J Cell Sci 1973; 12: 253-261.

[16] WIENER F, KLEIN G AND HARRIS H. The analysis of malignancy by cell fusion. VI. Hybrids between different tumour cells. J Cell Sci 1974; 16: 189-198.
[17] RIZVI AZ, SWAIN JR, DAVIES PS, BAILEY AS, DECKER $\mathrm{AD}$ et al. Bone marrow-derived cells fuse $\mathrm{w}$ ith normal and transformed intestinal stem cells. Proc Natl Acad Sci U S A 2006; 103: 6321-5. http://dx.doi.org/10.1073/ pnas.0508593103

[18] WEIMANN JM, CHARLTON CA, BRAZELTON TR, HACKMAN RC, BLAU HM. Contribution of transplanted bone marrow cells to Purkinje neurons in human adult brains. Proc Natl Acad Sci U S A 2003; 100: 2088-2093. http://dx.doi. org/10.1073/pnas.0337659100

[19] FERRARI G, CUSELLA-DE ANGELIS G, COLETTA M, PAOLUCCI E et al. Muscle regeneration by bone marrowderived myogenic progenitors. Science 1998; 279: 1528-1530. http://dx.doi.org/10.1126/science.279.5356.1528

[20] VASSILOPOULOS G, WANG PR AND RUSSELL DW. Transplanted bone marrow regenerates liver by cell fusion. Nature 2003; 422: 901-904. http://dx.doi.org/10.1038/nature01539

[21] WANG X, WILLENBRING H, AKKARI Y, TORIMARU Y, FOSTER $M$ et al. Cell fusion is the principal source of bonemarrow-derived hepatocyte. Nature 2003; 422: 897-901. http://dx.doi.org/10.1038/nature01531

[22] HUANG D, GAO Q, GUO L, ZHANG C, JIANG W et al. Isolation and identification of cancer stem-like cells in esophageal carcinoma cell lines. Stem Cells Dev 2009; 18: 465-473. http://dx.doi.org/10.1089/scd.2008.0033

[23] WANG J, GUO LP, CHEN LZ, ZENG YX, LU SH. Identification of cancer stem cell-like side population cells in human nasopharyngeal carcinoma cell line. Cancer Res 2007; 67: 3716-3724. http://dx.doi.org/10.1158/0008-5472.CAN-06$\underline{4343}$

[24] PARDAL R, CLARKE MF AND MORRISON SJ. Applying the principles of stem-cell biology to cancer. Nat Rev Cancer 2003; 3: 895-902. http://dx.doi.org/10.1038/nrc1232

[25] DEAN M, FOJO T AND BATES S. Tumor stem cells and drug resistance. Nat Rev Cancer 2005; 5: 275-84. http://dx.doi. org/10.1038/nrc1590

[26] HERMANN PC, HUBER SL, HERRLER T, AICHER A, ELLWART JW et al. Distinct populations of cancer stem cells determine tumor growth and metastatic activity in human pancreatic cancer. Cell Stem Cell 2007; 1: 313-323. http:// dx.doi.org/10.1016/j.stem.2007.06.002

[27] PETERS BA, DIAZ LA, POLYAK K, MESZLER L, ROMANS $K$ et al. Contribution of bone marrow-derived endothelial cells to human tumor vasculature. Nat Med 2005; 11: 261-262. http://dx.doi.org/10.1038/nm1200

[28] LYDEN D, HATTORI K, DIAS S, COSTA C, BLAIKIE P et al. Impaired recruitment of bone-marrow-derived endothelial and hematopoietic precursor cells blocks tumor angiogenesis and growth. Nat Med 2001; 7: 1194-1201. http://dx.doi. org/10.1038/nm1101-1194 